\title{
FERTILISATION RATE OBTAINED WITH FROZEN-THAWED BOAR SEMEN SUPPLEMENTED WITH ROSMARINIC ACID USING A SINGLE INSEMINATION TIMED ACCORDING TO VULVAR SKIN TEMPERATURE CHANGES
}

\author{
Victoria LuÑo*, Lydia GIL, Maite OlaCIREGUI, Juan GrandíA, Trinidad Ansó \\ and Ignacio DE BLAS \\ Department of Animal Pathology, Universidad de Zaragoza, C/Miguel Servet 177, 50013 \\ Zaragoza, Spain
}

(Received 3 July 2014; accepted 29 October 2014)

\begin{abstract}
Artificial insemination (AI) of sows with frozen-thawed semen usually results in lower pregnancy rates and litter sizes than the use of liquid preserved semen. The present study evaluated the effectiveness of vulvar skin temperature changes as a predictor of ovulation in sows and determined the fertility rates obtained after AI with frozen-thawed semen supplemented with rosmarinic acid (RA). Semen was collected from mature boars and cryopreserved in experimental extenders supplemented with or without $105 \mu \mathrm{M}$ of RA. Multiparous sows were inseminated with a single dose of semen when vulvar skin temperature decreased to a value below $35^{\circ} \mathrm{C}$. Intrauterine insemination was performed using $1.5 \times 10^{9}$ spermatozoa. The sows were slaughtered $48 \mathrm{~h}$ after AI and the embryos and oocytes were recovered from the oviducts. Total and progressive motility, viability and acrosome integrity were significantly $(\mathrm{P}<0.05)$ higher in RA-supplemented semen samples compared with the control. Fertilisation occurred in all sows inseminated in the study, although there were no significant differences between the experimental groups. Sows inseminated with RA-supplemented semen showed a slight increase in the number of embryos recovered as compared to sows inseminated with control semen. In conclusion, insemination according to vulvar skin temperature changes resulted in successful fertilisation in all sows, although supplementation of the freezing media with RA did not improve the fertilising ability of frozen-thawed boar sperm.
\end{abstract}

Key words: Artificial insemination, temperature, fertility, frozen-thawed boar sperm, rosmarinic acid

Improvements in the efficiency of pig breeding have been due to the use of different biotechnological advances. Artificial insemination (AI) is a tool widely used in intensive swine production. Most sows are artificially inseminated with fresh-refrigerated semen and less than $1 \%$ of sows with frozen-

*Corresponding author; E-mail: vicluno@unizar.es; Phone: 0034 (976) 844-113; Fax: 0034 (976) 761-612 
thawed (FT) semen (Johnson et al., 2000). Low fertilisation rates and additional cost are the main factors limiting the common use of FT semen in pig production. However, the use of FT semen has several benefits including long-term storage, control of transmission of certain pathogens, preservation of valuable genetic lines, and global gene distribution (Johnson et al., 2000; Bailey et al., 2008).

Several studies have focused on determining the factors underlying the poor quality of FT sperm and the variable farrowing rates and litter sizes obtained by its use (Johnson et al., 2000; Roca et al., 2006). Differences in freezability of semen among boars, as well as attempts to optimise cryopreservation protocols and packaging systems have been reported (Eriksson and RodriguezMartinez, 2000; Hernández et al., 2007). The high content of polyunsaturated fatty acids in the plasma membrane makes boar spermatozoa particularly sensitive during cryopreservation and produces molecular changes that decrease the lifespan of FT sperm (Cerolini et al., 2001). Studies on the incorporation of antioxidant compounds to improve the quality of FT semen have been extensive (Kaeoket et al., 2010; Malo et al., 2010; Malo et al., 2012), although the effect of antioxidant supplementation on sow fertility after AI is only marginally known. Antioxidant compounds from plant extracts, such as rosmarinic acid (RA), ameliorate the deleterious effects produced by oxidative stress during cryopreservation and improve sperm quality and in vitro fertilisation parameters when they are included in freezing extender solutions (Luño et al., 2014).

Despite these improvements in FT sperm quality, the fertility of FT sperm can be highly variable. Different strategies have been applied in order to achieve optimal fertility, including changes in the dosage and place of deposition of semen and the frequency or number of inseminations (Waberski et al., 1994; Roca et al., 2003). However, the main factor affecting fertility is the timing of insemination relative to the moment of ovulation (Bolarín et al., 2006). FT boar sperm have a short lifespan $(6-8 \mathrm{~h})$, thus AI must be performed close to the time of ovulation. Different physical and physiological traits such as body temperature, vulvar reddening, sexual hormone levels, genital electrical resistance and genital mucus arborisation may be used to determine the moment of ovulation in sows (Rojkittikhun et al., 1992; Soede et al., 1994; Luño et al., 2012; Luño et al., 2013). Vulvar skin temperature changes during oestrus have been described in several species (Junge-Wentrup and Holtz, 1984; Soede et al., 1997). On the basis of digital infrared thermographic measurements, Scolari et al. (2011) reported that skin temperature in the vulvar and gluteal areas decreased several hours prior to ovulation. In addition, we have observed that vulvar and ear skin temperature decreased significantly in the periovulatory period (Luño et al., 2013).

The aim of this study was to evaluate the fertilisation rate after insemination performed according to vulvar temperature changes observed around the time of ovulation. In addition, we studied the effect of rosmarinic acid supplementation of the freezing extender on the fertility rates of sows after AI. 


\section{Materials and methods}

\section{Reagents and media}

All chemicals were obtained from Sigma-Aldrich Quimica, S.A. (Madrid, Spain) unless otherwise indicated. Orvus Es Paste (OEP) was from Minitüb (Tiefenbach, Germany).

\section{Animals}

The experimental study was conducted at a commercial pig breeding farm located in Zaragoza (Spain). On the day of weaning, multiparous crossbred sows (Landrace $\times$ Large White) were housed on straw in individual pens. The sows were fed a commercial diet $(2150 \mathrm{Kcal}$ metabolisable energy $/ \mathrm{kg}, 14 \%$ crude protein and $0.7 \%$ lysine) once a day, and water was provided ad libitum. The care and use of animals were in accordance with the Spanish Policy for Animal Protection RD1201/05, which meets the provisions of Directive 86/609/EEC of the European Union regarding the protection of animals used for experimental and other scientific purposes.

\section{Semen collection and freezing-thawing protocol}

The sperm-rich fraction was collected from 6 mature fertile boars (Duroc) using the gloved-hand method. The semen was extended 1:2 in isothermal Beltsville Thawing Solution (BTS) for transportation. Sperm concentration, motility, acrosome integrity and normal morphology were microscopically evaluated by standard laboratory techniques, and only high quality semen was selected for the experiments.

Cryopreservation of sperm was carried out using the straw freezing procedure described by Westendorf et al. (1975). After cooling to $15^{\circ} \mathrm{C}$, samples were centrifuged at $1500 \times \mathrm{g}$ for $3 \mathrm{~min}$ and the supernatant was discarded. The remaining semen was divided into two aliquots, a control sample and an experimental sample that was supplemented with $105 \mu \mathrm{M}$ RA. Each semen aliquot was diluted in lactose-egg yolk (LEY) base extender containing 20\% (v:v) egg yolk, $80 \%$ of $11 \%$ L-lactose solution $(290 \mathrm{mM})$ and $100 \mu \mathrm{g} / \mathrm{ml}$ of kanamycin sulphate to yield a semen concentration of approximately $1.5 \times 10^{9} / \mathrm{ml}$. The sperm suspensions were cooled gradually from $15{ }^{\circ} \mathrm{C}$ to $5{ }^{\circ} \mathrm{C}$ during $2 \mathrm{~h}$ and then slowly diluted (2:1) with LEY extender with $1.5 \%$ OEP and $9 \%$ glycerol. The final sperm concentration to be frozen was $1 \times 10^{9} / \mathrm{ml}$, with $3 \%$ glycerol. The resuspended and cooled semen was loaded into $0.5 \mathrm{ml}$ straws and sealed. The sperm samples were frozen in static nitrogen vapour $(4 \mathrm{~cm}$ above the liquid nitrogen for $20 \mathrm{~min}$ ) and were plunged into liquid nitrogen for storage. Semen samples from each group were thawed by immersing the straws in a circulating water bath at $37^{\circ} \mathrm{C}$ for $21 \mathrm{sec}$ and then resuspending the semen in BTS $\left(1: 4\right.$, v:v; $\left.37^{\circ} \mathrm{C}\right)$. 


\section{Analysis of semen quality}

Motility (percentage of total and progressively motile sperm) was measured by means of a computer-assisted semen analysis (CASA) system (ISAS ${ }^{\circledR}$, Proiser, Valencia, Spain). For each evaluation, a $5-\mu 1$ semen sample was placed in a pre-warmed Makler counting chamber.

Plasma membrane and acrosome integrity was evaluated simultaneously using fluorescein isothiocyanate conjugated with peanut agglutinin (FITC-PNA) and propidium iodide (PI) staining. An aliquot of $500 \mu \mathrm{l}$ of semen suspension from each treatment group was supplemented with $10 \mu \mathrm{l}$ of FITC-PNA solution $(1 \mathrm{mg} / \mathrm{ml})$ and $12 \mu \mathrm{M}$ of PI solution, incubated at $38^{\circ} \mathrm{C}$ for $5 \mathrm{~min}$, and finally fixed in paraformaldehyde $(4 \%[\mathrm{v} / \mathrm{v}])$ in saline solution. At least 200 spermatozoa were examined under a fluorescence phase-contrast microscope and the proportion of spermatozoa with intact plasma and acrosome membrane (PNA-/PI-) was determined.

\section{Detection of oestrus and insemination}

Detection of oestrus began two days after weaning. The sows were checked twice daily by allowing them to have nose-to-nose contact with a mature boar and by applying pressure to their back. The onset of oestrus was defined as the exhibition of a standing reflex in the presence of the boar. The insemination time was selected by measuring vulvar skin temperature (Luño et al., 2013). Temperature was determined using a thermo-precision infrared forehead thermometer (Chicco, Grandate, Italy). The thermometer measures the infrared radiation given off by the surface of the forehead and converts this value into the corresponding temperature. The thermometer detects body temperature from a distance of $0.5 \mathrm{~cm}$ up to a distance of $10 \mathrm{~cm}$ from the skin. The sensitivity of the thermometer is $\pm 0.2^{\circ} \mathrm{C}$.

AIs were performed with a single dose of semen when vulvar skin temperature decreased to a value below $35^{\circ} \mathrm{C}$. For intrauterine insemination (IUI), the sows were randomly allocated to two groups: FT control sperm $(\mathrm{n}=10)$ and FT RA sperm $(n=12)$. A deep insemination device (Magaplus, Magapor, Ejea de los Caballeros, Spain) was used. The catheter was inserted through the vagina and locked into the cervical canal. The flexible catheter was inserted though the exterior catheter and deposited the semen into the uterus. The semen dose contained $1.5 \times 10^{9}$ spermatozoa in $50 \mathrm{ml}$ of BTS. After insemination, approximately $3 \mathrm{ml}$ of BTS was flushed through the cannula to introduce the remaining spermatozoa.

\section{Recovery of embryos and oocytes}

Sows were slaughtered $48 \mathrm{~h}$ after AI and their reproductive tracts were collected. Each oviduct was separated from the uterus and flushed with 4\% BSA 
in PBS from the infundibulum through the uterotubal junction. The embryos and oocytes obtained were evaluated under a stereomicroscope.

\section{Parameter assessment}

The recovery rate was defined as the number of embryos and oocytes recovered divided by the number of corpora lutea. The fertilisation rate was determined as the number of embryos divided by the total number of embryos plus oocytes recovered.

\section{Statistical analysis}

Statistical analyses were performed using SPSS version 17.0 for Windows. Student's $t$-tests were used to evaluate the significance of differences between the two groups in terms of sperm motility, sperm membrane integrity, number of ovulations, number of embryos, recovery rate and fertilisation rate. All data were expressed as the mean $\pm \mathrm{SEM}$, and $\mathrm{P}<0.05$ was considered significant.

\section{Results}

\section{Effect of RA on sperm quality}

The presence of RA in semen samples significantly increased both total and progressive sperm motility $(\mathrm{P}<0.05)$ compared to untreated controls $(58.9 \pm 1.1 \%$ vs. $48.5 \pm 1.6 \%$ and $36.7 \pm 2.1 \%$ vs. $26.1 \pm 2.1 \%$, respectively). The proportion of spermatozoa with intact plasma and acrosomal membranes was higher in samples supplemented with RA than in the controls $(56.7 \pm 1.7 \%$ vs. $46.7 \pm 1.1 \%, \mathrm{P}<0.05)$.

\section{Effect of $R A$ and insemination time on fertilisation rate}

The study was performed with 22 sows, but four sows were excluded from subsequent analyses because their dissected tissues showed evidence of ovarian cysts. Therefore, the results were based on 18 sows. The weaning to oestrus interval was $86.7 \pm 5.1 \mathrm{~h}$ and the oestrus to AI interval was $34.8 \pm 5.9 \mathrm{~h}$. The temperature of the vulvar skin at the time of AI was $34.4 \pm 0.3{ }^{\circ} \mathrm{C}$.

The number of ovulations, the number of embryos, the recovery rate and the fertilisation rate are summarised in Table 1 . The number of ovulations was $22.3 \pm 6.7$ and $21.4 \pm 5.1$ in the control and RA groups, respectively. The recovery rate was higher in the RA group than in the control, although it was above $77 \%$ in both groups. Fertilisation occurred in all sows inseminated in the study. However, there were no significant differences between the groups with respect to fertilisation rate $(55.3 \%$ vs. $56.6 \%)$. Sows inseminated with RA-supplemented semen showed a slight increase in the number of embryos recovered compared to sows inseminated with control semen (9.7 vs. 9.4). 
Table 1

Effect of a single insemination according to vulvar skin temperature changes in the periovulatory period with frozen-thawed (FT) boar semen supplemented with rosmarinic acid (RA) on embryo production and fertility rates

\begin{tabular}{lrrr}
\hline \multirow{2}{*}{ Parameters } & \multicolumn{2}{c}{ Treatments } & \multirow{2}{*}{ P value } \\
\cline { 2 - 3 } & \multicolumn{1}{c}{ FT control } & \multicolumn{1}{c}{ FT RA } & \\
\hline Number of sows & \multicolumn{1}{c}{8} & 10 & \\
Number of ovulations & $22.3 \pm 2.1$ & $21.4 \pm 1.8$ & 0.217 \\
Number of embryos & $9.4 \pm 0.8$ & $9.7 \pm 0.4$ & 0.629 \\
Recovery rate (\%) & $77.1 \pm 0.3$ & $86.4 \pm 0.5$ & 0.291 \\
Fertilisation rate (\%) & $56.6 \pm 0.3$ & $55.3 \pm 0.3$ & 0.877 \\
\hline
\end{tabular}

Recovery rate $=$ number of embryos and oocytes $/$ number of corpora lutea. Fertilisation rate $=$ number of embryos $/$ number of embryos and oocytes. The results are given as mean $\pm \mathrm{SEM}$

\section{Discussion}

The interval between $\mathrm{AI}$ and ovulation is a major factor affecting swine fertility, particularly when cryopreserved sperm with a short lifespan is used (Waberski et al., 1994). We evaluated in vivo fertility after AI depending on vulvar skin temperature changes in the periovulatory period using FT sperm supplemented with $105 \mu \mathrm{M}$ RA.

Different strategies have been employed to determine the time of ovulation, such as the duration of oestrus, ultrasonographic measurement of preovulatory follicle diameter, or hormone determinations (Soede et al., 1994; Lucy et al., 2001). However, these methods are time consuming, invasive and not practical for routine use in swine farms. In this study, we performed AI in sows depending on vulvar skin temperature modifications. In a previous study we established that the temperature of vulvar and ear skin decreased significantly around the time of ovulation (Luño et al., 2013). The drop in temperature occurred between $12 \mathrm{~h}$ and $0 \mathrm{~h}$ prior to ovulation, and then the temperature returned to normal values. These findings are in agreement with the observations of Scolari et al. (2011) who detected a decrease in skin temperature in the vulvar and gluteal area several hours before ovulation, as measured by digital infrared thermography. We detected a similar drop in temperature and we inseminated the sows when the vulvar skin temperature was less than $35^{\circ} \mathrm{C}$.

FT spermatozoa have a limited lifespan in the female genital tract. In addition, ovulation occurs approximately $36 \mathrm{~h}$ (ranges: 10 to $58 \mathrm{~h}$ ) after the onset of oestrus (Soede et al., 1995). The best fertility and farrowing rates with FT sperm are achieved when insemination is performed $6-8 \mathrm{~h}$ before ovulation (Waberski et al., 1994). In this study, the sows were inseminated once between $12 \mathrm{~h}$ and $0 \mathrm{~h}$ 
before ovulation. We recovered embryos in all sows, although the fertilisation rates obtained were around $56 \%$. The fertility rates achieved in this study were lower than those obtained using FT sperm in spontaneously ovulating sows inseminated once or twice with a deep intrauterine catheter $(>67 \%)$ (Bolarín et al., 2009; Yamaguchi et al., 2009). Bertani et al. (1997) obtained a fertility rate of $78 \%$ after a single insemination $6 \mathrm{~h}$ before ovulation, but in that study synchronised sows were used. The timing of insemination with FT semen is critical because the duration of sperm fertility is reduced (Waberski et al., 1994), and a single insemination with FT results in reduced fertility (Johnson et al., 1982). However, Spencer et al. (2010) did not find differences between single and double insemination using FT sperm at $24 \mathrm{~h}$ and $32 \mathrm{~h}$ after the detection of oestrus.

Despite its limited use in pig farms, FT sperm can yield pregnancy rates higher than $77 \%$ and litter sizes of more than 10 fetuses. These results are achieved through the use of repeated deep intrauterine AI with $2 \times 10^{9}$ spermatozoa (Johnson et al., 1982; Roca et al., 2003; Roca et al., 2006) or double cervical AI with $6 \times 10^{9}$ spermatozoa (Roca et al., 2011). The sperm dose has a variable effect on fertility and farrowing rates (Larsson et al., 1977; Johnson et al., 1982), but using the smallest number of spermatozoa has economic advantages. Spencer et al. (2010) tested single and double AI with $1 \times 10^{9}$ motile spermatozoa and obtained pregnancy rates higher than $70 \%$ and 9.5 normal fetuses on the average. We used $1.5 \times 10^{9}$ spermatozoa (a number similar to that used in the cooled semen procedure) and achieved an embryo recovery rate of approximately $55 \%$. This relatively low value may be related to boar fertility, sperm concentration or the use of a single AI.

Many studies have been conducted to improve the quality and lifespan of sperm during cryopreservation. The addition of antioxidant substances to the freezing extender enhances the survival of sperm (Alvarez and Storey, 1995). In a previous study we found that $105 \mu \mathrm{M}$ RA preserved sperm motility and quality at 120 min post-thawing due to the scavenging activity of RA (Luño et al., 2014). In this study, sperm motility and membrane integrity were significantly higher after thawing in semen samples treated with RA as compared to the control. The in vitro fertilising capacity of sperm samples treated with RA was also higher than that of the control sperm (Luño et al., 2014). However, for unknown reasons, RA supplementation did not enhance in vivo fertilisation rates after AI. During the cryopreservation process, capacitation-like changes are induced, and only uncapacitated spermatozoa bind to oviductal epithelial cells (Petrunkina et al., 2001). Although RA-treated sperm exhibited a lower degree of plasma membrane and acrosomal membrane damage, RA did not increase fertilisation rates in vivo. Yamaguchi and Funahashi (2012) reported that AI with FT boar semen supplemented with beta-mercaptoethanol did not increase pregnancy or farrowing rates. However, Estrada et al. (2014) established that the supplementation of freezing media with reduced glutathione affected the in vivo fertilising ability of 
boar semen. The presence of $2 \mathrm{mM}$ reduced glutathione in the freezing media increased the farrowing rates and the total number of piglets born.

In conclusion, we showed that a single intrauterine insemination with FT boar sperm timed according to vulvar skin temperature decreases during the periovulatory period resulted in successful fertilisation in all the sows used. Moreover, the supplementation of freezing extender with $105 \mu \mathrm{M}$ RA did not improve the in vivo fertilising ability of FT spermatozoa.

\section{Acknowledgements}

This study was supported by the University of Zaragoza (UZ 2011-BIO-03), Zaragoza, Spain. The authors would like to thank the staff of Agro-test-Control S. L. and Gran Loma S. L. for their technical assistance.

\section{References}

Alvarez, J. G. and Storey, B. T. (1995): Differential incorporation of fatty acids into and peroxidative loss of fatty acids from phospholipids of human spermatozoa. Mol. Reprod. Dev. 42, 334-346.

Bailey, J. L., Lessard, C., Jacques, J., Brèque, C., Dobrinski, I., Zeng, W. and Galantino-Homer, H. L. (2008): Cryopreservation of boar semen and its future importance to the industry. Theriogenology 70, 1251-1259.

Bertani, G. R., Scheid, I. R., Fialho, F. B., Rubin, M. I., Wentz, I. and Gonçalves, P. B. (1997): Effect of the time of artificial insemination with frozen-thawed or fresh semen on embryo viability and early pregnancy rate in gilts. Theriogenology 48, 933-945.

Bolarín, A., Roca, J., Rodríguez-Martínez, H., Hernández, M., Vázquez, J. M. and Martínez, E. A. (2006): Dissimilarities in sows' ovarian status at the insemination time could explain differences in fertility between farms when frozen-thawed semen is used. Theriogenology $\mathbf{6 5}$, 669-680.

Bolarín, A., Hernández, M., Vazquez, J. M., Rodriguez-Martinez, H., Martinez, E. A. and Roca, J. (2009): Use of frozen-thawed semen aggravates the summer-autumn infertility of artificially inseminated weaned sows in the Mediterranean region. J. Anim. Sci. 87, 3967-3975.

Cerolini, S., Maldjian, A., Pizzi, F. and Gliozzi, T. M. (2001): Changes in sperm quality and lipid composition during cryopreservation of boar semen. Reproduction 121, 395-401.

Eriksson, B. M. and Rodriguez-Martinez, H. (2000): Effect of freezing and thawing rates on the post-thaw viability of boar spermatozoa frozen in FlatPacks and Maxi-straws. Anim. Reprod. Sci. 63, 205-220.

Estrada, E., Rodríguez-Gil, J. E., Rocha, L. G., Balasch, S., Bonet, S. and Yeste, M. (2014): Supplementing cryopreservation media with reduced glutathione increases fertility and prolificacy of sows inseminated with frozen-thawed boar semen. Andrology 2, 88-99.

Hernández, M., Roca, J., Gil, M. A., Vázquez, J. M. and Martínez, E. A. (2007): Adjustments on the cryopreservation conditions reduce the incidence of boar ejaculates with poor sperm freezability. Theriogenology 67, 1436-1445.

Johnson, L. A., Aalbers, J. G. and Arts, J. A. (1982): Use of boar spermatozoa for artificial insemination. II. Fertilizing capacity of fresh and frozen spermatozoa in gilts inseminated either at a fixed time or according to Walsmeta readings. J. Anim. Sci. 54, 126-131. 
Johnson, L. A., Weitze, K. F., Fiser, P. and Maxwell, W. M. (2000): Storage of boar semen. Anim. Reprod. Sci. 62, 143-172.

Junge-Wentrup, S. and Holtz, W. (1984): Body temperature as a means to monitor reproductive functions in sows and cows. 10th International Congress of Animal Reproduction and Artificial Insemination, 10-14 June 1984, University of Illinois, Urbana-Champaign, Illinois, USA. Volume II. Brief Communications. Paper 141, 3 pp.

Kaeoket, K., Chanapiwat, P., Tummaruk, P. and Techakumphu, M. (2010): Supplemental effect of varying L-cysteine concentrations on the quality of cryopreserved boar semen. Asian J. Androl. 12, 760-765.

Larsson, K., Einarsson, S. and Swensson, T. (1977): The development of a practicable method for deep freezing of boar spermatozoa. Nord. Vet. Med. 29, 113-118.

Lucy, M., Liu, J., Boyd, C. and Bracken, C. (2001): Ovarian follicular growth in sows. Reproduction 58, 31-45.

Luño, V., Gil, L., Jerez, R. A., Malo, C., Galé, I. and de Blas, I. (2012): Crystallisation pattern of vestibular mucus and its relation to vestibular electrical resistance in cycling sow. Vet. Rec. 171, 298.

Luño, V., Gil, L., Jerez, R. A., Malo, C., González, N., Grandía, J. and de Blas, I. (2013): Determination of ovulation time in sows based on skin temperature and genital electrical resistance changes. Vet. Rec. 172, 579.

Luño, V., Gil, L., Olaciregui, M., González, N., Jerez, R. A. and de Blas, I. (2014): Rosmarinic acid improves function and in vitro fertilising ability of boar sperm after cryopreservation. Cryobiology 69, 157-162.

Malo, C., Gil, L., Gonzalez, N., Martínez, F., Cano, R., de Blas, I. and Espinosa, E. (2010): Antioxidant supplementation improves boar sperm characteristics and fertility after cryopreservation: comparison between cysteine and rosemary (Rosmarinus officinalis). Cryobiology 61, 142-147.

Malo, C., Gil, L., Cano, R., González, N. and Luño, V. (2012): Fennel (Foeniculum vulgare) provides antioxidant protection for boar semen cryopreservation. Andrologia 44, 710-715.

Petrunkina, A., Friedrich, J., Drommer, W., Bicker, G., Waberski, D. and Töpfer-Petersen, E. (2001): Kinetic characterization of the changes in protein tyrosine phosphorylation of membranes, cytosolic $\mathrm{Ca}^{2+}$ concentration and viability in boar sperm populations selected by binding to oviductal epithelial cells. Reproduction 122, 469-480.

Roca, J., Carvajal, G., Lucas, X., Vazquez, J. M. and Martinez, E. A. (2003): Fertility of weaned sows after deep intrauterine insemination with a reduced number of frozen-thawed spermatozoa. Theriogenology 60, 77-87.

Roca, J., Parrilla, I., Rodriguez-Martinez, H., Gil, M. A., Cuello, C., Vazquez, J. M. and Martinez, E. A. (2011): Approaches towards efficient use of boar semen in the pig industry. Reprod. Domest. Anim. 46, 79-83.

Roca, J., Vázquez, J. M., Gil, M. A., Cuello, C., Parrilla, I. and Martínez, E. A. (2006): Challenges in pig artificial insemination. Reprod. Domest. Anim. 41, 43-53.

Rojkittikhun, T., Einarsson, S., Edqvist, L., Uvnäs-Moberg, K. and Lundeheim, N. (1992): Relationship between lactation-associated body weight loss, levels of metabolic and reproductive hormones and weaning-to-oestrous interval in primiparous sows. Zentralbl. Veterinarmed. A 39, 426-432.

Scolari, S., Clark, S., Knox, R. and Tamassia, M. (2011): Vulvar skin temperature changes significantly during estrus in swine as determined by digital infrared thermography. J. Swine Health Prod. 19, 151-155.

Soede, N. M., Hazeleger, W., Broos, J. and Kemp, B. (1997): Vaginal temperature is not related to the time of ovulation in sows. Anim. Reprod. Sci. 47, 245-252.

Soede, N., Helmond, F. and Kemp, B. (1994): Periovulatory profiles of oestradiol, LH and progesterone in relation to oestrus and embryo mortality in multiparous sows using transrectal ultrasonography to detect ovulation. J. Reprod. Fertil. 101, 633-641. 
Soede, N., Wetzels, C., Zondag, W., de Koning, M. and Kemp, B. (1995): Effects of time of insemination relative to ovulation, as determined by ultrasonography, on fertilization rate and accessory sperm count in sows. J. Reprod. Fertil. 104, 99-106.

Spencer, K. W., Purdy, P. H., Blackburn, H. D., Spiller, S. F., Stewart, T. S. and Knox, R. V. (2010): Effect of number of motile, frozen-thawed boar sperm and number of fixed-time inseminations on fertility in estrous-synchronized gilts. Anim. Reprod. Sci. 121, 259-266.

Waberski, D., Weitze, K. F., Gleumes, T., Schwarz, M., Willmen, T. and Petzoldt, R. (1994): Effect of time of insemination relative to ovulation on fertility with liquid and frozen boar semen. Theriogenology 42, 831-840.

Westendorf, P., Richter, L. and Treu, H. (1975): Deep freezing of boar sperma. Laboratory and insemination results using the Hülsenberger paillete method. Dtsch. Tierarztl. Wochenschr. 82, 261-267.

Yamaguchi, S. and Funahashi, H. (2012): Effect of the addition of beta-mercaptoethanol to a thawing solution supplemented with caffeine on the function of frozen-thawed boar sperm and on the fertility of sows after artificial insemination. Theriogenology 77, 926-932.

Yamaguchi, S., Funahashi, H. and Murakami, T. (2009): Improved fertility in gilts and sows after artificial insemination of frozen-thawed boar semen by supplementation of semen extender with caffeine and $\mathrm{CaCl}_{2}$. J. Reprod. Dev. 55, 645-649. 